\title{
The Influence of Fracture Strain Energy on the Burst Tendency of Coal Seams and Field Application
}

\author{
Hongjun Guo $\mathbb{D}^{1},{ }^{1}$ Ming Ji $\left(\mathbb{D},{ }^{2}\right.$ Dapeng Liu $\mathbb{D}^{1},{ }^{1}$ Mengxi Liu, ${ }^{1}$ and Weisheng Zhao ${ }^{3}$ \\ ${ }^{1}$ Jiangsu Vocational Institute of Architectural Technology, Xuzhou 221116, China \\ ${ }^{2}$ Key Laboratory of Deep Coal Resource Mining, Ministry of Education of China, School of Mines, \\ China University of Mining \& Technology, Xuzhou 221116, China \\ ${ }^{3}$ Institute of Mining Engineering, Guizhou Institute of Technology, Guiyang 550003, China \\ Correspondence should be addressed to Ming Ji; jiming@cumt.edu.cn
}

Received 11 December 2020; Revised 18 February 2021; Accepted 1 April 2021; Published 14 April 2021

Academic Editor: Yu-Wei Chen

Copyright ( $\odot 2021$ Hongjun Guo et al. This is an open access article distributed under the Creative Commons Attribution License, which permits unrestricted use, distribution, and reproduction in any medium, provided the original work is properly cited.

\begin{abstract}
Coal is typically considered a special engineering rock mass because of its low strength, high internal fracture development, good permeability, and random distribution of microparticles and fractures. The results of cyclic loading and unloading tests indicate that the strain energy during the coal deformation process can be divided into three parts: plastic strain energy; fracture strain energy; and base-material strain energy. The energy composition ratio differs depending on coal strength. Lower proportions of fracture strain energy are associated with higher elastic energy indexes, and there is a negative correlation between fracture strain energy and other coal burst tendency indexes. The results were applied on the 4206 isolated island working face of coal mine A in Yan'an, Shanxi, China, yielding good benefits. The findings presented here provide a theoretical basis for understanding the principle of coal seam bursting and guidance for reducing burst risks.
\end{abstract}

\section{Introduction}

As a special engineering rock mass, coal bodies typically have poor integrity, low strength, a high degree of fracture development, and random distribution of internal grains and fractures [1]. Coal and rock have been extensively studied within the fields of mechanics and energy [2-8]. Coal production conditions are affected by several factors including the natural environment, production, and technology, all of which can lead to complex mining conditions. Numerous studies have investigated coal bodies from a range of perspectives including fine and microscopic characteristics $[9,10]$, acoustic emission characteristics of coal body deformation and failure [11], bedding effects [12], size effects [13,14], water content [14-17], temperature [14], gas content [18], and coal-rock combination [19, 20].

Liu et al. [21] proposed that a rock burst is most likely to occur when the coal body reaches its maximum elastic energy index. The calculation formula of the elastic energy index was revised by Xiao et al. [22] by analyzing the relationship between the hysteresis loop and strain energy during cyclic loading and unloading. The coal burst tendency index was redefined by Cai et al. [23] on the basis of the damage statistical constitutive model. Numerical simulations have also been used to study coal burst tendencies $[19,24]$.

Coal bodies are massive porous and multifracture media; however, the influence of cracks on their burst tendency has been scarcely addressed in the aforementioned studies. In this paper, the influence of cracks on the strain energy of a coal body is considered during the process of coal deformation and failure. The composition of energy is re-divided [25], and the influence of crack strain energy on the burst tendency is discussed.

\section{Theoretical Background}

The coal deformation and failure process obey the law of energy conservation. Under uniaxial cyclic loading, the only external work force acting on a specimen is the axial load 
from the test machine. The coal strain energy $w$ (Figure 1) can be expressed as the sum of the elastic strain energy $w_{e}$ and plastic strain energy $w_{p}$ :

$$
\left\{\begin{array}{l}
w=w_{e}+w_{p}, \\
w=\int_{0}^{\varepsilon_{1}} \sigma_{1+} \mathrm{d} \varepsilon_{1}, \\
w_{e}=\int_{\varepsilon_{p}}^{\varepsilon_{1}} \sigma_{1-} \mathrm{d} \varepsilon_{1},
\end{array}\right.
$$

where $\sigma_{1+}$ and $\sigma_{1-}$ are the loading stress and unloading stress, respectively.

The deformation of a coal body can be divided into basematerial deformation and fracture deformation on the basis of composition. During the initial unloading stage, the behavior of the internal cracks within a coal does not immediately change from compression to expansion. Rebound deformation is therefore mainly caused by elastic deformation of the base material, and the stress-strain curve is approximately linear [25].

In Figure 2, a tangent line $\mathrm{AC}$ can be drawn in the section with good linear rebound during the initial unloading stage. The area of $\mathrm{ABC}$ is the base-material strain energy $w_{g}$ generated by the coal during a load cycle:

$$
w_{g}=\frac{1}{2} \sigma_{1 u} \varepsilon_{g},
$$

where $\sigma_{1 u}$ is the stress at an unloading point and $\varepsilon_{g}$ is the reversible strain of coal base material.

The fracture strain energy $w_{c}$ is then

$$
w_{c}=w_{e}-w_{g} .
$$

Equations (1)-(3) can be used to analyze the relationship between different strain energies.

\section{Materials and Methods}

Owing to the poor formability of the coal body, the coal samples were processed into cylindrical $(\Phi 50 \times \mathrm{H} 100 \mathrm{~mm})$ or cuboid specimens (L50 $\times$ W50 $\times \mathrm{H} 100 \mathrm{~mm}$ ) in accordance with national standards, as shown in Figure 3.

Experiments were performed using a coal and rock mechanical property test machine at China University of Mining and Technology (Figure 4) using the following protocol.

(1) In the conventional uniaxial compression experiments, the displacement control mode was adopted with a loading rate of $0.02 \mathrm{~mm} / \mathrm{s}$ to obtain the average uniaxial compressive strength $\sigma_{c}$ of the coal specimens.

(2) The cyclic loading and unloading experiments also adopted the displacement control mode and loading/unloading rate of $0.02 \mathrm{~mm} / \mathrm{s}$. The unloading began when the load reached $75 \%-80 \%$ of $\sigma_{c}$ and ended at $1 \%-5 \% \sigma_{c}$. The loading then continued. Following this approach, the loading and unloading process was repeated, increasing

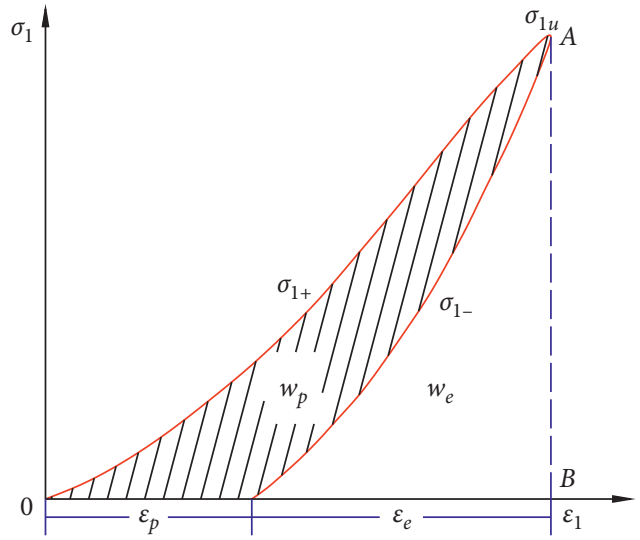

FIgURE 1: Conventional calculation of strain energy.

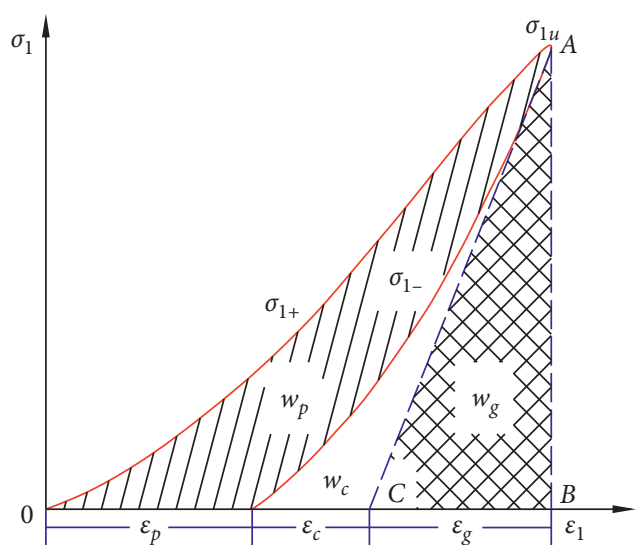

Figure 2: Classification and calculation of strain energy.

the loading stress level by $5 \% \quad \sigma_{c}$ during each subsequent cycle until the sample was destroyed.

\section{Results and Discussion}

4.1. Coal Mine A in Yan'an, Shanxi. The stress-strain curves of coal samples obtained from the conventional uniaxial compression experiments are shown in Figure 5. The average uniaxial compressive strength is $8.30 \mathrm{MPa}$. The strain energies obtained from the uniaxial cyclic loading and unloading experiments are given in Table 1.

The elastic strain energy of the coal samples dominates during the loading and unloading process prior to failure and is approximately $63.71 \%$ of the input energy, of which the fracture strain energy accounts for $20.14 \%$.

4.2. Coal Mine B in Xianyang, Shanxi. The average uniaxial compressive strength of coal samples is $19.53 \mathrm{MPa}$ (Figure 6). The strain energy is listed in Table 2.

Table 2 shows that nearly $70 \%$ of the input energy is converted to elastic strain energy, of which the proportion of fracture strain energy is less than $20 \%$. Compared with coal sample A, the coal sample from coal mine B is hard and contains a low degree of fracture development. 


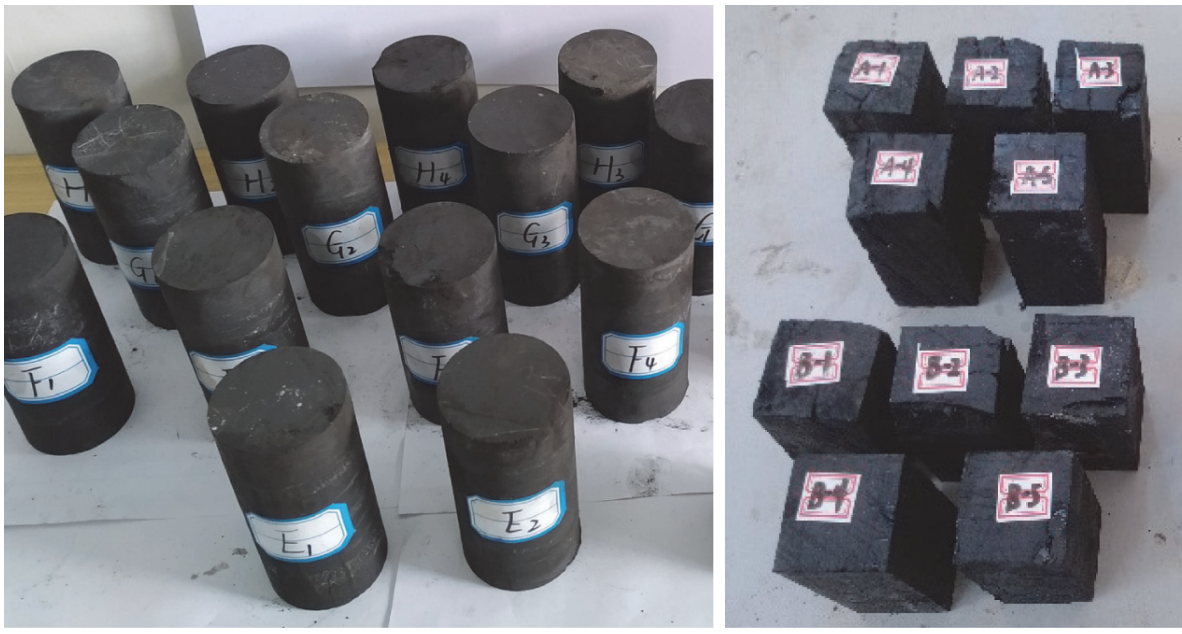

Figure 3: Coal samples.

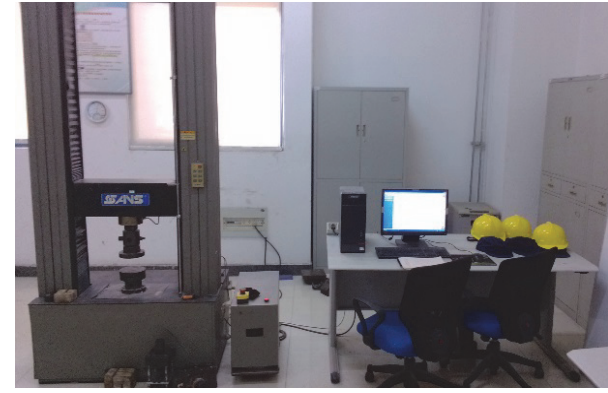

Figure 4: SANS test system.

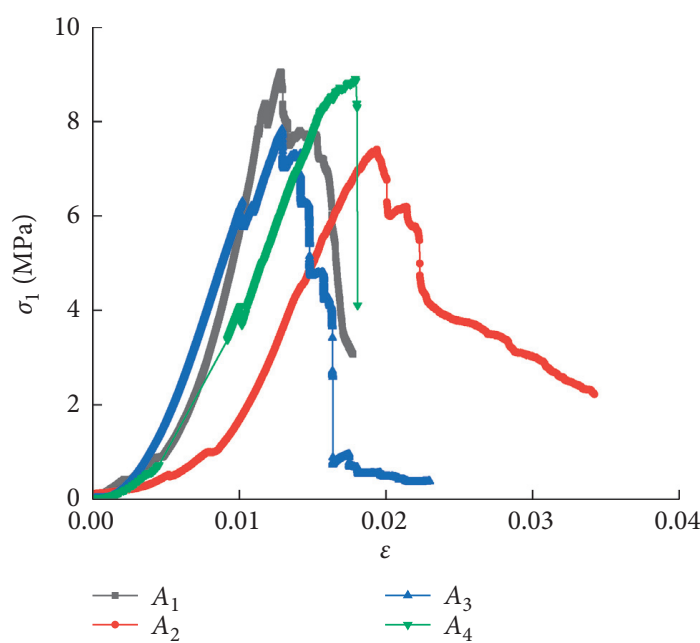

FIGURE 5: Stress-strain curves of coal samples from coal mine A.

Because the fracture rebound deformation lags behind that of the base material at a given moment (e.g., during the initial unloading stage), smaller fracture strain energy ratios during the unloading process until stabilization are associated with more abrupt and rapid rebound deformation. To some extent, this reflects that brittle failure tends to occur more easily in hard coal with fewer fractures.
4.3. Coal Mine $C$ in Tieling, Liaoning. In these samples, the average uniaxial compressive strength is found to be 8.87 MPa (Figure 7), and the strain energy is listed in Table 3.

The strain energy composition in samples from coal mine $\mathrm{C}$ is similar to that in samples from coal mine $\mathrm{A}$. The elastic strain energy accounts for $65.67 \%$, of which $17.08 \%$ is fracture strain energy.

The elastic energy index $W_{E T}$ is an indicator for testing the burst tendency of a coal seam and can be expressed as

$$
W_{E T}=\frac{w_{e}}{w_{p}} .
$$

Equation (4) shows that the elastic energy indexes of coal mines A, B, and C are 1.80, 2.74, and 1.99, respectively. This indicates that greater proportions of elastic strain energy (and lower proportions of fracture strain energy) are associated with a higher possibility of severe failure during unloading, namely, a higher burst tendency.

To analyze the influence of coal fracture degree on its burst tendency, the proportion of fracture strain energy and corresponding burst tendency index of the coal body (uniaxial compressive strength, dynamic failure time, elastic energy index, and burst energy index) were determined (Table 4).

As shown in Figure 8, the variation between the ratio of fracture strain energy and burst tendency index is uniform with regard to the energy composition of the loaded coal samples. As the ratio increases, the burst tendency of each index decreases to different extents.

The above conclusions explain why low-strength, highpermeability, and poor-integrity coal is not prone to burst accidents, which is a key for mitigation measures to relieve pressure in coal seams with higher burst risk.

A series of measures, such as on-site coal loose blasting and large-diameter bore pressure relief, can be used to convert a portion of the strain energy that can be instantaneously released in the coal into fracture strain energy to release the hysteresis. This reduces the strength of the instantaneous release of the burst coal body and decreases the burst risk. 
TABLE 1: Strain energy of coal samples from coal mine A.

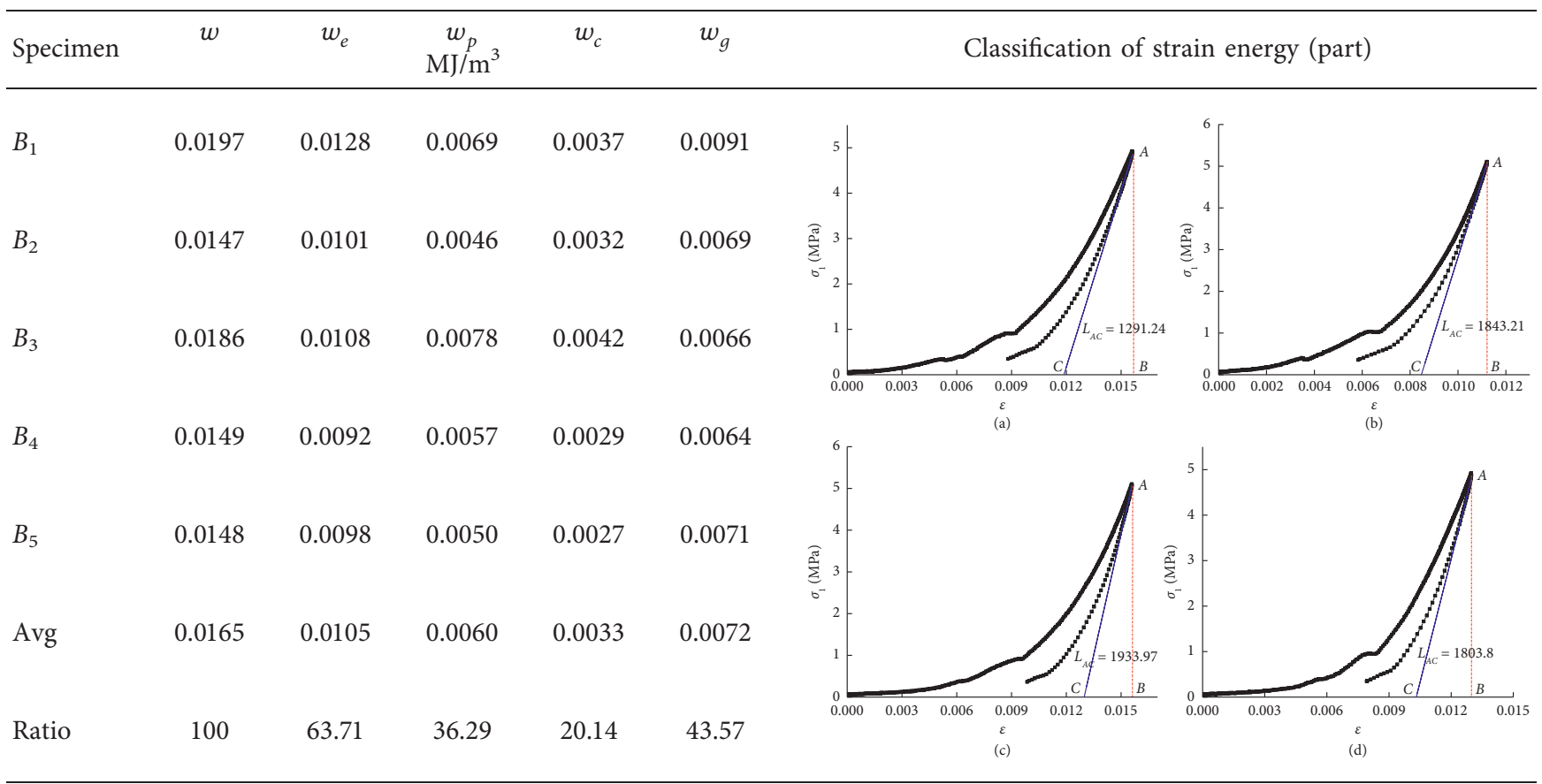

Note. The ratio refers to the ratio of different strain energy to input energy, namely, $\left(w_{i} / w\right) \times 100 \%, \quad i=e, p, c, g$.

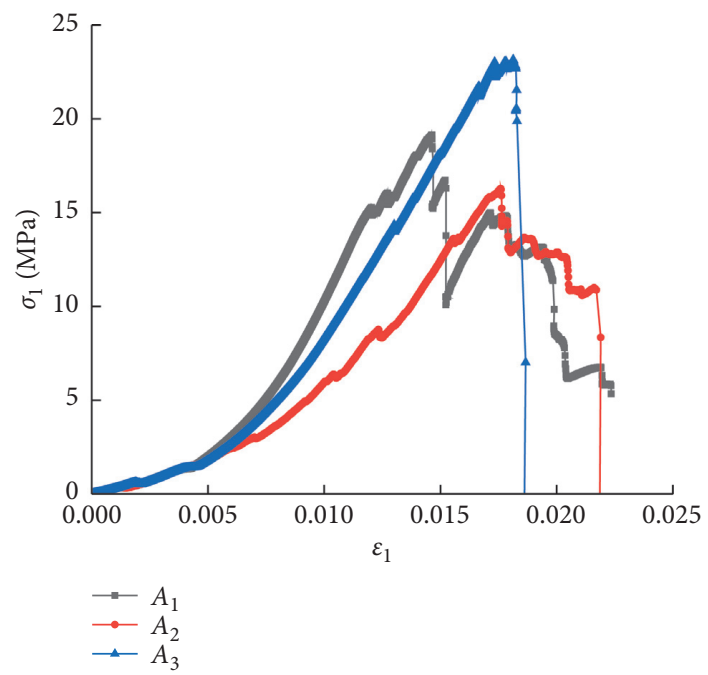

Figure 6: Stress-strain curves of coal samples from coal mine B.

4.4. Field Application. The 4206 working face in coal mine A is an island working face, as shown in Figure 9, and the section coal pillar width is $15 \mathrm{~m}$. The coal seam with a burial depth of approximately 565-657 $\mathrm{m}$ and average thickness of $8.25 \mathrm{~m}$ has a weak burst tendency and a sandstone roof. The production conditions indicate that strong ground pressure or rock burst may occur during the advance of the working face.

To ensure safe mining of the working face, the relationship between fracture strain energy and burst tendency index and pressure relief measures are combined in the areas with higher burst risk and the following measures are applied.

(1) Roof presplitting blasting (Figure 10): this cuts off the connection of the overburden roof, loosens the top coal, and reduces the stress concentration in the coal body.

(2) Pressure relief of large-diameter holes in the side (Figure 11): this plays the role of energy absorption, hole closure, and pressure relief and reduces the internal energy accumulation in the coal body. 
TABLE 2: Strain energy of coal samples from coal mine B.

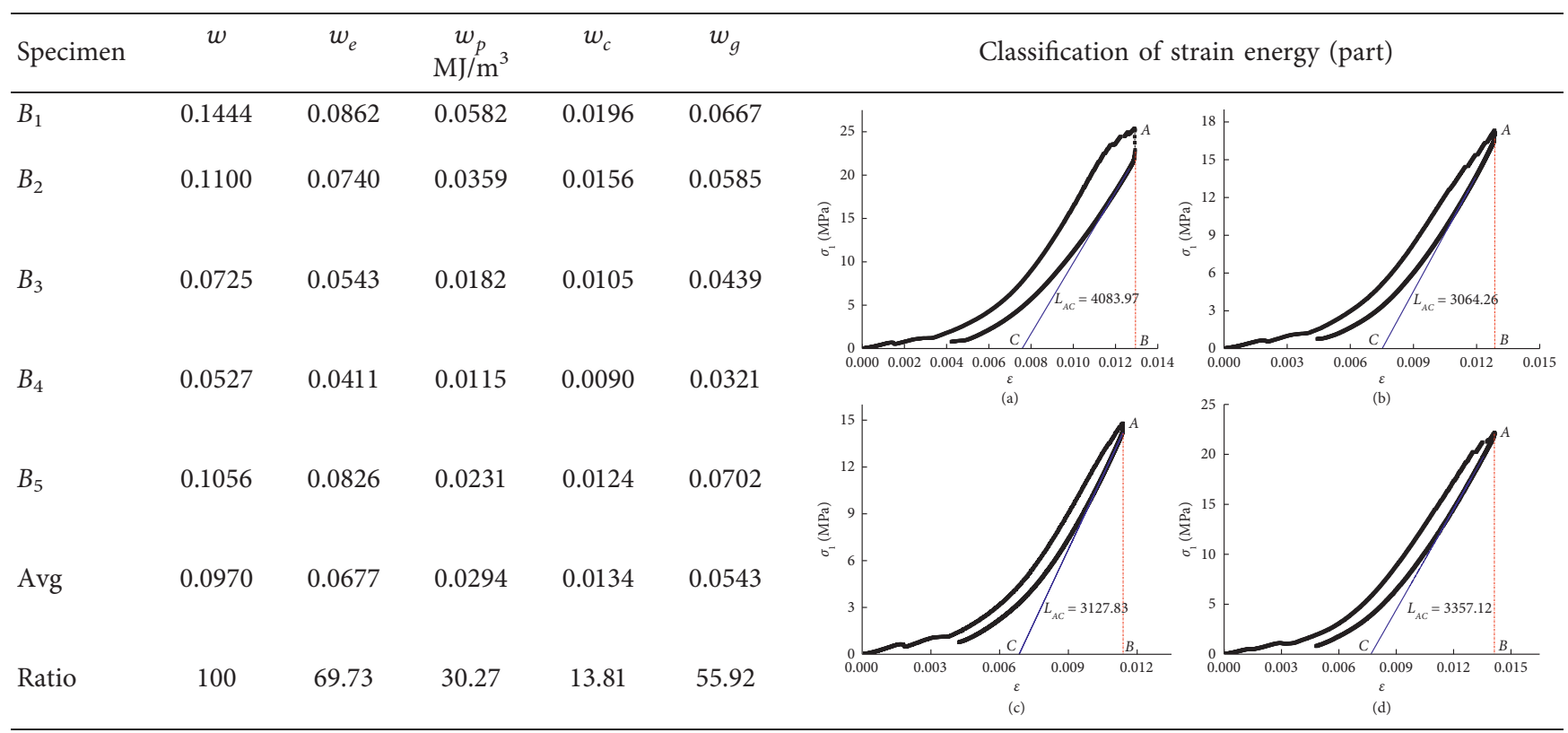

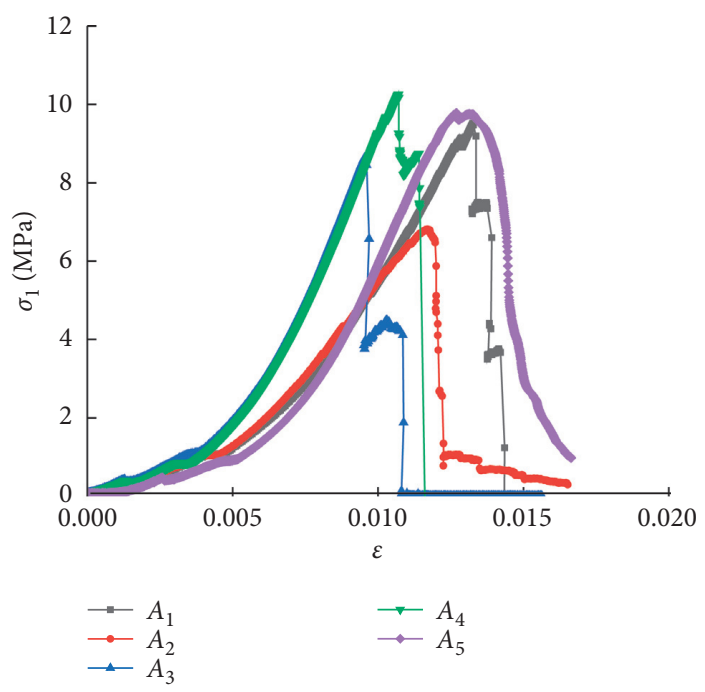

Figure 7: Stress-strain curves of coal samples from coal mine C.

(3) Figure 12 shows the relief of roof blasting pressure in the working face. This can loosen the top coal and shallow sandstone roof, which is beneficial to avoid top coal caving and direct roof collapse after mining in the large-area hanging roof in the goaf.

After applying the above measures, the normal working resistance of the hydraulic support during mining is found to be $22-35 \mathrm{MPa}$, which is slightly higher than that of the conventional working face $(18-32 \mathrm{MPa})$ and no abnormal change is observed. The maximum pressure during the initial weighting and "square effect" period is close to $60 \mathrm{MPa}$, and the maximum pressure during the periodic weighting reaches up to $50 \mathrm{MPa}$. The overall appearance of the ground pressure is not particularly intense. Previous studies have shown that the minimum energy required for microseismic occurrences in a coal body is at least $1.0 \times 10^{5} \mathrm{~J}$ [26]. Figure 13 shows the microseismic monitoring data over a six-month period, during which the minimum required energy exceeded 25 times and the corresponding maximum magnitude was 0.87 (Table 5). This indicates that the above pressure relief measures played a role and achieved the purpose of improving the anti-burst and safety conditions. The working face is presently withdrawn and the technical and economic benefits have been achieved. 
TABLE 3: Strain energy of coal samples from coal mine C.

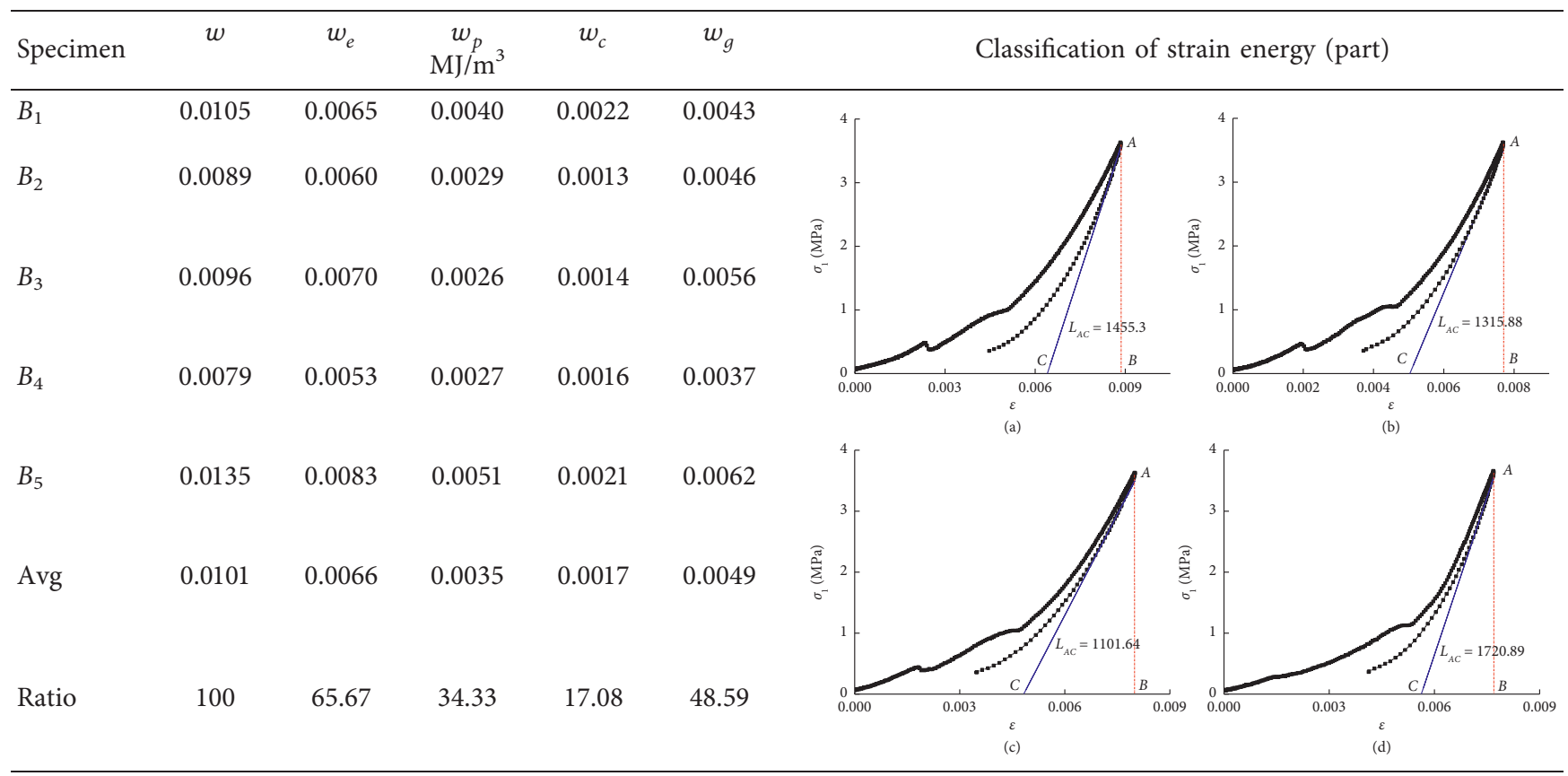

TABLE 4: Fracture strain energy and burst tendency index.

\begin{tabular}{|c|c|c|c|c|c|}
\hline Coal mine & $\left(w_{c} / w\right)(\%)$ & $\sigma_{c}(\mathrm{MPa})$ & $D_{T}(\mathrm{~ms})$ & $W_{E T}$ & $K_{E}$ \\
\hline $\mathrm{A}$ & 20.14 & 8.3 & 1695.4 & 1.8 & 2.175 \\
\hline B & 13.81 & 19.53 & 1166.4 & 2.74 & 12.885 \\
\hline $\mathrm{C}$ & 17.08 & 8.87 & 1478 & 1.99 & 2.27 \\
\hline
\end{tabular}

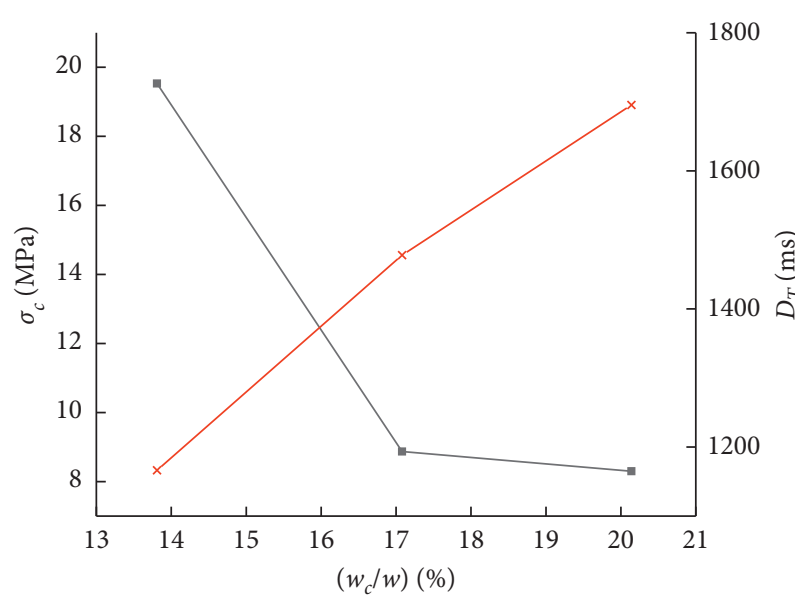

$$
\begin{aligned}
& \rightarrow \sigma_{c} \\
& -x-D_{T}
\end{aligned}
$$

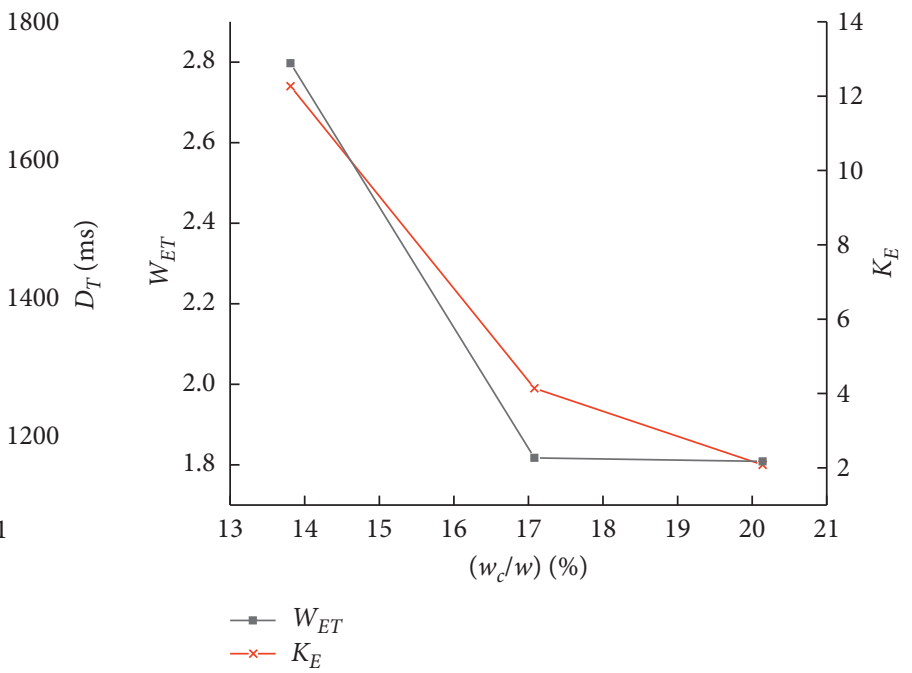

(a)

(b)

Figure 8: Relationship between fracture strain energy and burst tendency index. 


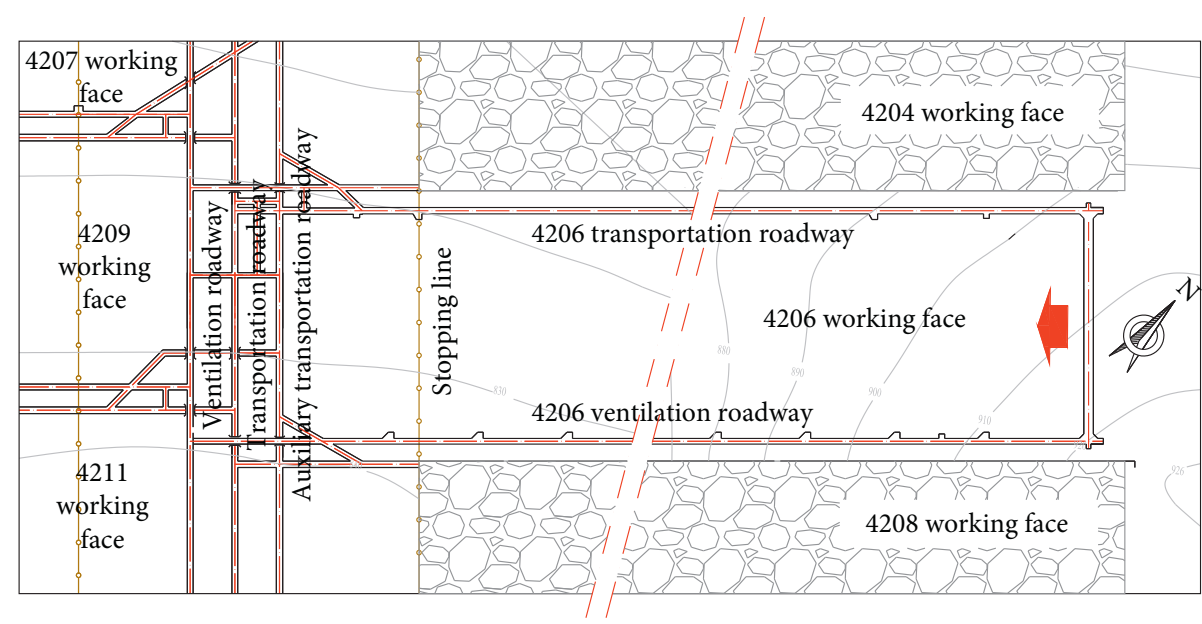

Figure 9: Layout of 4206 working face.

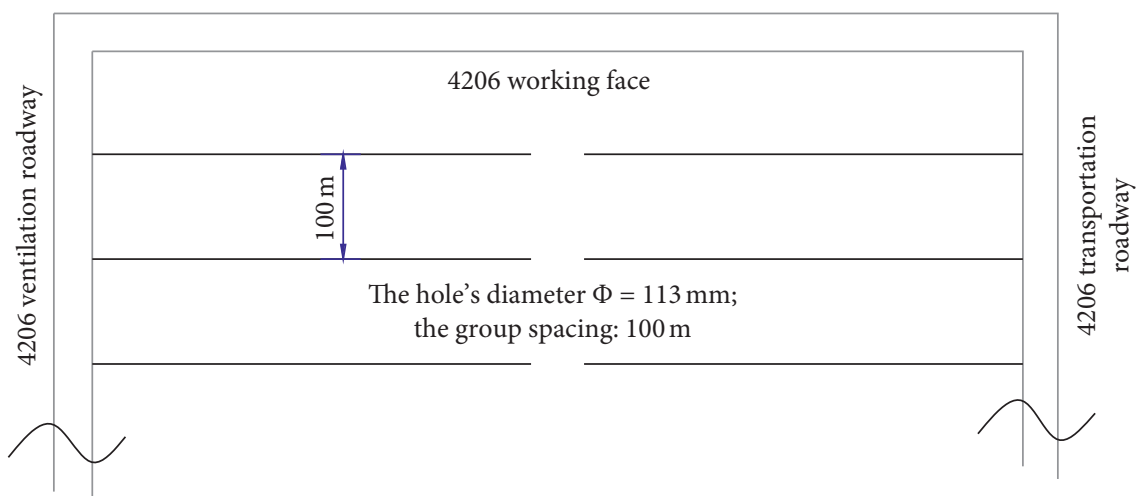

(a)

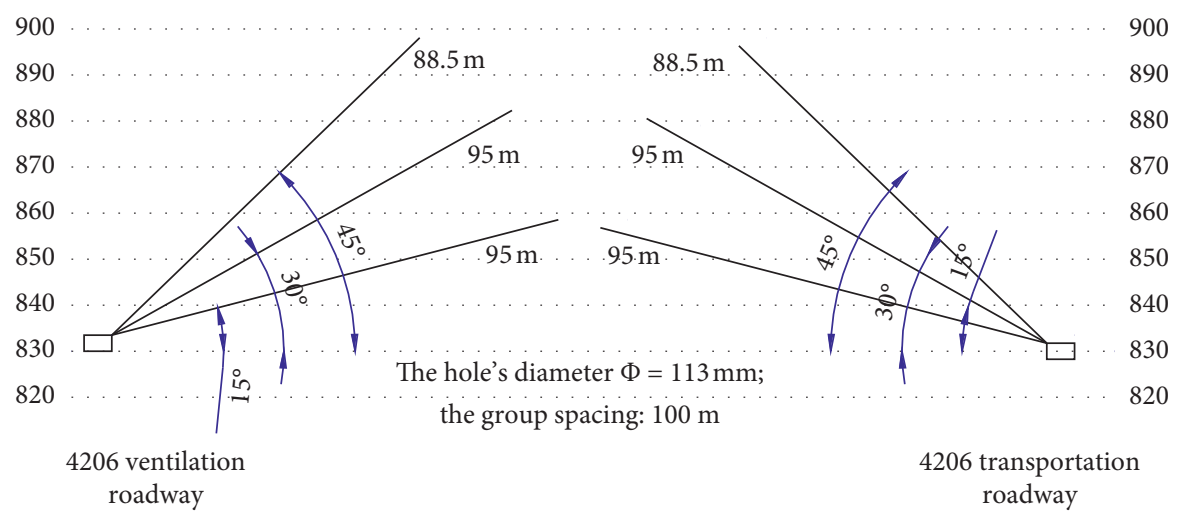

(b)

Figure 10: Layout of presplitting blasting holes in roof. (a) Plan. (b) Profile. 


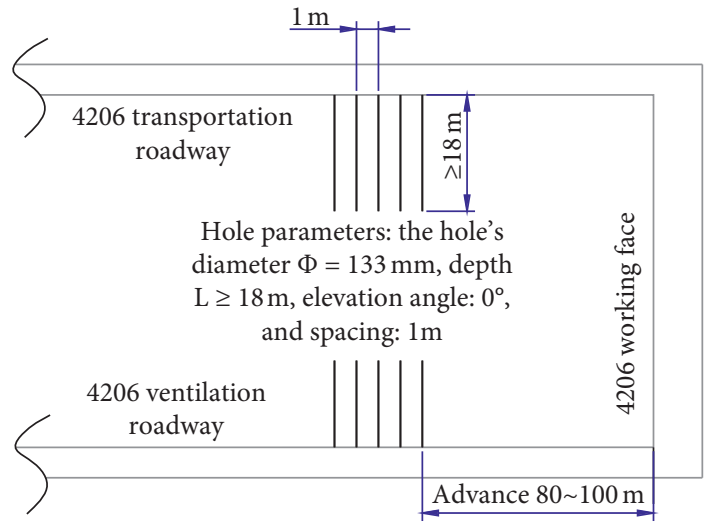

(a)

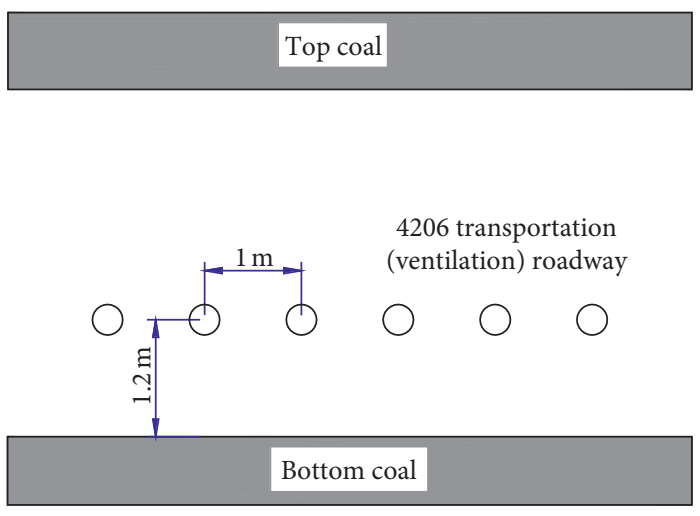

(b)

Figure 11: Layout of large-diameter holes. (a) Plan. (b) Profile.

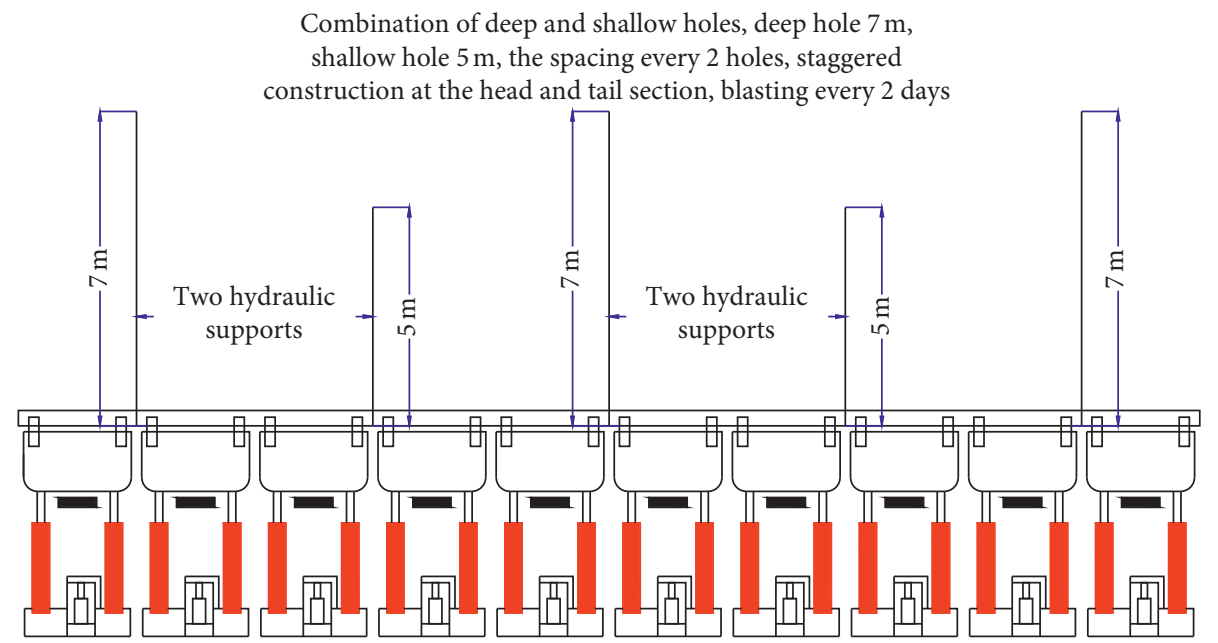

FIGURE 12: Layout of pressure relief holes in the working face roof.

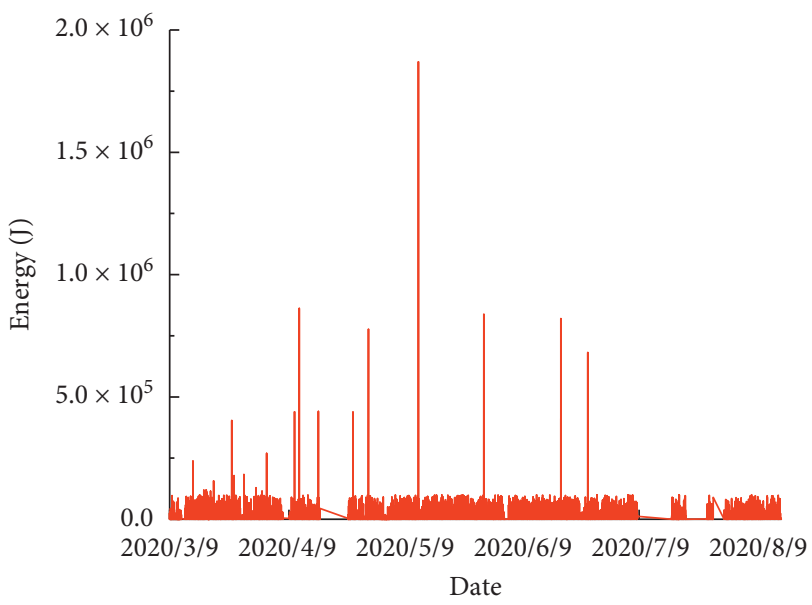

(a)

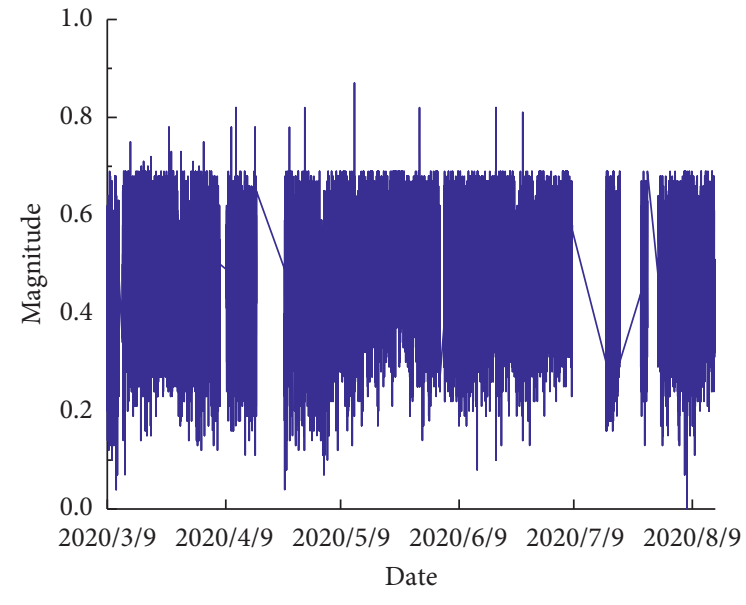

(b)

Figure 13: Microseismic monitoring data. (a) Energy. (b) Magnitude. 
TABLe 5: High-energy frequency statistics.

\begin{tabular}{lccc}
\hline Date & $10^{5} \mathrm{~J} \leq E<10^{6} \mathrm{~J}$ & $E \geq 10^{6} \mathrm{~J}$ & Maximum magnitude \\
\hline March & 11 & 0 & 0.78 \\
April & 7 & 0 & 0.82 \\
May & 3 & 1 & 0.87 \\
June & 3 & 0 & 0.82 \\
July & 0 & 0 & 0.69 \\
August & 0 & 0 & 0.69 \\
Total & 24 & 1 & Max $(0.87)$ \\
\hline
\end{tabular}

\section{Conclusions}

The results of the uniaxial and cyclic loading/unloading experiments on coal allow the following conclusions to be made.

(1) The energy composition of a coal body under cyclic loading and unloading can be re-divided. The elastic strain energy consists of fracture strain energy and base-material strain energy.

(2) Under the action of cyclic loading and unloading, the ratio of energy composition differs for coal samples with different strengths. The elastic strain energy accounts for $63.71 \%-69.73 \%$ of the input energy, of which the fracture strain energy accounts for $13.81 \%-20.14 \%$. Coal with a lower ratio of fracture strain energy shows a higher elastic energy index, which implies that the corresponding coal seam has a higher burst tendency.

(3) There is a negative correlation between the ratio change of fracture strain energy in coal and its burst tendency index, which provides a theoretical basis for coal seams with high strength, low permeability, and good integrity to explain the principle of pressure relief, reduce burst risk, and provide important guidance for engineering practice.

\section{Data Availability}

The data used to support the findings of the study are available from the corresponding author upon request.

\section{Conflicts of Interest}

The authors declare that they have no conflicts of interest.

\section{Acknowledgments}

This study was supported by the Jiangsu University Natural Science Research Project (20KJB560032), Jiangsu University Natural Science Research Project (Key) (18KJA560001), Guizhou Science and Technology Plan Project (Guizhou Science and Technology Cooperation Support ([2019]2882) and Guizhou Science and Technology Cooperation Platform Talents ([2017]5789-12)), Xuzhou Science and Technology Project (KC17156), Jiangsu Construction System Science and Technology Project (Guidance) (2020ZD30, 2019ZD080, and 2019ZD070), and Educational Science
Research Project (Key) (ES2020-6). The authors thank Esther Posner, PhD, from Liwen Bianji, Edanz Editing China (http://www.liwenbianji.cn/ac), for editing the English text of a draft of this manuscript.

\section{References}

[1] S. J. Wang, "Geological nature of rock and its deduction for rock mechanics," Chinese Journal of Rock Mechanics and Engineering, vol. 28, no. 3, pp. 433-450, 2009.

[2] H. Guo, M. Ji, and D. Liu, "Transition threshold of granite mechanical characteristics at high temperature," Advances in Civil Engineering, vol. 2020, no. 3, 10 pages, 2020.

[3] H. Munoz, A. Taheri, and E. K. Chanda, "Fracture energybased brittleness index development and brittleness quantification by pre-peak strength parameters in rock uniaxial compression," Rock Mechanics and Rock Engineering, vol. 49, no. 12, pp. 4587-4606, 2016.

[4] Y. Xue, P. G. Ranjith, F. Dang et al., "Analysis of deformation, permeability and energy evolution characteristics of coal mass around borehole after excavation," Natural Resources Research, vol. 29, no. 5, pp. 3159-3177, 2020.

[5] H. J. Guo, M. Ji, Y. D. Zhang, and M. Zhang, "Study of effect on mechanical property of rock under uniaxial cyclic loading and unloading," Advances in Civil Engineering, vol. 2018, Article ID 1670180, 6 pages, 2018.

[6] A. Momeni, M. Karakus, G. R. Khanlari, and M. Heidari, "Effects of cyclic loading on the mechanical properties of A granite," International Journal of Rock Mechanics and Mining Sciences, vol. 77, pp. 89-96, 2015.

[7] M. Ji, K. Chen, and H. J. Guo, "Constitutive model of rock uniaxial damage based on rock strength statistics," Advances in Civil Engineering, vol. 2018, Article ID 5047834, 8 pages, 2018.

[8] J. Liu, X. Liang, Y. Xue, K. Yao, and Y. Fu, "Numerical evaluation on multiphase flow and heat transfer during thermal stimulation enhanced shale gas recovery," Applied Thermal Engineering, vol. 178, pp. 1-16, 2020.

[9] Y. X. Zhao, Y. D. Jiang, and Y. Zhang, "The relationship between bump-prone properity and micro-structure characteristics of coal," Journal of China Coal Society, vol. 1, pp. 64-68, 2007.

[10] W. G. Liu, Y. D. Jiang, H. W. Zhou, and Z. H. Chen, "Experimental study on outburst proneness coal seam of meso character and fracture destabilization," Journal of Hunan University of Science and Technology (Natural Science Edition), vol. 4, pp. 14-18, 2006.

[11] H. Y. Li, Z. X. Sun, Q. X. Qi, F. M. Li, and S. K. Zhao, "Deformation rules and acoustic emission characteristics of coal with different outburst proneness," Journal of Liaoning 
Technical University (Natural Science), vol. 36, no. 12, pp. 1251-1256, 2017.

[12] X. J. Hao, L. Yuan, S. H. Wang et al., "Study on bedding effect of bump tendency for hard coal," Coal Science and Technology, vol. 46, no. 5, pp. 1-7, 2018.

[13] Y. K. Shi, Y. H. Ma, and Y. C. Yin, "Research on size effect affected to seam bump-prone test results," Coal Science and Technology, vol. 42, no. 2, pp. 23-26, 2014.

[14] H. J. Su, Q. Yin, H. W. Jing, and H. H. Zhao, "Research on bearing capacity and burst proneness of coal samples from western shallow-buried coal seam," Journal of Mining and Safety Engineering, vol. 32, no. 2, pp. 227-232+239, 2015.

[15] X. B. Mao, Z. Q. Chen, S. P. Xu, and T. Z. Li, "Experimental study on the relation between the burst tendency and water content in coal seam," Chinese Journal of Rock Mechanics and Engineering, vol. 1, pp. 49-52, 2001.

[16] B. Liang, M. Tian, and J. G. Wang, "Effect of different water contents on bursting potential of hard coal seam," Journal of Water Resources and Water Engineering, vol. 25, no. 1, pp. 100-102, 2014.

[17] C. D. Su, X. X. Zhai, X. Z. Wei, and B. F. Li, "Influence of saturation period on bursting liability indices for coal seam \#2 in qianqiu coal mine," Chinese Journal of Rock Mechanics and Engineering, vol. 33, no. 2, pp. 235-242, 2014.

[18] G. H. Zhang, Z. H. OoYang, Q. X. Qi, H. Y. Li, Z. G. Deng, and J. J. Jiang, "Experimental Research on the influence of gas on coal burst tendency," Journal of China Coal Society, vol. 42, no. 12, pp. 3159-3165, 2017.

[19] S. K. Zhao, Y. Zhang, R. J. Han, H. B. Jiang, N. B. Zhang, and Z. J. Xu, "Numerical simulation experiments on bursting liability evolution of compound coal-rock structure," Journal of Liaoning Technical University (Natural Science), vol. 32, no. 11, pp. 1441-1446, 2013.

[20] Z. L. Mu, H. Wang, P. Peng, Z. J. Liu, and X. C. Yang, "Experimental Research on failure characteristics and bursting liability of rock-coal-rock sample," Journal of Mining and Safety Engineering, vol. 30, no. 6, pp. 841-847, 2013.

[21] J. W. Liu, B. X. Huang, and M. T. Wei, "Influence of cyclic uniaxial loading on coal elastic-plastic properties and energy accumulation and dissipation," Journal of Liaoning Technical University (Natural Science), vol. 31, no. 1, pp. 26-30, 2012.

[22] F. K. Xiao, Z. L. Shen, G. Liu, Z. Zhang, and Z. R. Zhang, "Relationship between hysteresis loop and elastoplastic strain energy during cyclic loading and unloading," Chinese Journal of Rock Mechanics and Engineering, vol. 33, no. 9, pp. 17911797, 2014.

[23] W. Cai, L. M. Dou, R. J. Han, G. H. Zhang, and X. W. Li, "Bursting liability of coal based on damage statistical constitutive model," Journal of China Coal Society, vol. 36, no. S2, pp. 346-352, 2011.

[24] L. S. Song, S. K. Zhao, J. Liu, X. Z. Wei, R. J. Han, and H. B. Jiang, "“Experimental Research on rules of rock burst tendency evolution and mechanical properties of "roof-coal" structure body," Journal of China Coal Society, vol. 39, no. S1, pp. 23-30, 2014.

[25] H. Fu, S. Wang, X. Pei, and W. Chen, "Indices to determine the reliability of rocks under fatigue load based on strain energy method," Applied Sciences, vol. 9, no. 3, p. 360, 2019.

[26] H. He, L. M. Dou, S. Y. Gong, P. Zhou, and Z. J. Xue, "Rock burst rules induced by cracking of overlying key stratum," Chinese Journal of Geotechnical Engineering, vol. 32, no. 8, pp. 1260-1265, 2010. 